\title{
Troponin as a Prognostic Factor of Brain Injury in Military Field Hospitals
}

\author{
Mohammad Javad Behzadnia ${ }^{1 *}$ \\ ${ }^{1}$ Trauma Research Center, Baqiyatallah University of Medical Sciences, Tehran, Iran \\ *Corresponding Author: Mohammad Javad Behzadnia, M.D., Assistant Professor, Trauma Research Center, Baqiyatallah \\ University of Medical Sciences, Nosrati Alley, Sheikh Bahaie St., Molla Sadra St., Vanaq Sq., Tehran, Iran. Tel.: +98- \\ 2181262012,Email: Behzadnia@bmsu.ac.ir
}

Received January 7, 2020; Accepted March 4, 2020; Online Published March 15, 2020

$\mathrm{T}$ rauma is one of the leading causes of death in many countries. Almost every day we in trauma centers are confronted by various civil traumatic injuries. Among them, head trauma can result in some major chronic disabilities. Every year, many people, especially young men, are involved in car accidents, falling or occupational traumas which lead to brain injuries. Moderate to severe head trauma could impose permanent sequels such as paraplegia, quadriplegia, or other severe neurological disorders, which may result in a large socioeconomic burden.

Many nations are now experiencing both national and international terrorist attacks. Traumatic brain injuries (TBIs) have become more prevalent and severe during recent decades, especially in the Middle East.

Time-saving investigational studies could aid in rapid pathological investigation and treatment. Neuroimaging such as brain computed tomography (CT) scan and magnetic resonance imaging (MRI) play critical roles in diagnosing acute head trauma. Hence, these modalities show even the pathologies which may not develop during the first hours of the injuries in a well-equipped civil hospital. A lack of such facilities and more dominant severe head trauma in a military field could worsen the situation. Unfortunately, most military field hospitals do not have neuroimaging facilities, but laboratory tests such as those measuring troponin could help healthcare providers. Certainly, proper decision-making under such dire conditions will lead to more lives being saved.

While a traumatic brain injury may occur as a result of acute myocardial infarction (MI), it may lead to increased cardiac enzymes, such as troponin I, independently. In some TBIs, neurogenic stunned myocardium occurs due to catecholamine release from the myocardial nerve ending. In this condition, troponin I and the other cardiac enzymes may be increased. This phenomenon is related to a higher risk of mortality.1,2

More accurate history taking and considering cardiovascular problems may distinguish between these two reasons. Therefore, it is strongly recommended that trauma patients be managed as a whole, even in a crowded emergency department.

Among the prognostic and predictive factors, the cardiac enzyme troponin I could help predict the severity of a traumatic brain injury (TBI). This may be useful, especially in developing countries where doctors must deal with limited medical equipment in remote areas. It could be used in military situations and field hospitals to decide whether to observe a victim or refer him to a higher level trauma center as a probable critical case during the following hours.

Recent different studies have shown that high troponin I levels could predict a poor prognosis in TBIs and therefore, higher hospital mortality rates. ${ }^{3-8}$

The military forces are comprised mainly of young men; hence, a positive troponin test after a TBI could be more reliable in predicting the severity of a brain injury.

Almost all of the recent studies have agreed with the important role of troponin in predicting the outcome of the purest TBI, but it is essential to note that cardiac problems such as acute MI may occur concomitantly with head trauma. Some studies have recommended that other cardiac enzymes be used to assess simultaneous cardiac injuries. This is more important in cases of head and chest trauma. ${ }^{9}$

Interestingly, a bidirectional aspect can be encountered: cardiac problems and neurogenic-induced cardiac injuries that both have their value in patients' decision making. ${ }^{10}$

As a simple and easily available test, troponin I could be used to better evaluate and treat TBI. Thus, it could be strongly suggested as a test in civil trauma centers and may even be used in military medicine as a severity index

Copyright $($ C 2020 The Author(s). This is an open-access article distributed under the terms of the Creative Commons Attribution License (http:// creativecommons.org/licenses/by/4.0), which permits unrestricted use, distribution, and reproduction in any medium, provided the original work is properly cited. 
for casualties with combat brain injuries. However; more studies should be conducted to better assess its accuracy.

\section{Conflict of Interest Disclosures}

The author declares no conflicts of interest.

\section{Ethical Approval}

Not applicable.

\section{References}

1. Mierzewska-Schmidt M, Gawecka A. Neurogenic stunned myocardium - do we consider this diagnosis in patients with acute central nervous system injury and acute heart failure? Anaesthesiol Intensive Ther. 2015;47(2):175-180. doi:10.5603/ ait.2015.0017.

2. Rimaz S, Ashraf A, Marzban S, et al. Significance of cardiac troponin I elevation in traumatic brain injury patients. Anesth Pain Med. 2019;9(2):e90858. doi:10.5812/aapm.90858.

3. El-Menyar A, Asim M, Latifi R, Bangdiwala SI, Al-Thani $\mathrm{H}$. Predictive value of positive high-sensitivity troponin $\mathrm{T}$ in intubated traumatic brain injury patients. J Neurosurg. 2018;129(6):1541-1549. doi:10.3171/2017.7.jns17675.

4. Cai SS, Bonds BW, Hu PF, Stein DM. The role of cardiac troponin I in prognostication of patients with isolated severe traumatic brain injury. J Trauma Acute Care Surg. 2016;80(3):477-483. doi:10.1097/ta.0000000000000916.
5. Prathep S, Sharma D, Hallman M, et al. Preliminary report on cardiac dysfunction after isolated traumatic brain injury. Crit Care Med. 2014;42(1):142-147. doi:10.1097/ CCM.0b013e318298a890.

6. Najafipour H, Siahposht Khachaki A, Khaksari M, Shahouzehi B, Joukar S, Poursalehi HR. Traumatic brain injury has not prominent effects on cardiopulmonary indices of rat after 24 hours: hemodynamic, histopathology, and biochemical evidence. Iran Biomed J. 2014;18(4):225-231. doi:10.6091/ ibj.13222.2014.

7. Hasanin A, Kamal A, Amin S, et al. Incidence and outcome of cardiac injury in patients with severe head trauma. Scand Trauma Resusc Emerg Med. 2016;24:58. doi:10.1186/s13049016-0246-z.

8. Bender M, Stein M, Schoof B, Kolodziej MA, Uhl E, Schöller K. Troponin I as an early biomarker of cardiopulmonary parameters during the first $24 \mathrm{~h}$ of intensive care unit treatment in isolated traumatic brain injury patients. Injury. 2020. doi:10.1016/j.injury.2020.01.002.

9. Lippi G, Buonocore R, Mitaritonno M, Cervellin G. Cardiac troponin I is increased in patients with polytrauma and chest or head trauma. Results of a retrospective case-control study. J Med Biochem. 2016;35(3):275-281. doi:10.1515/jomb-20160010.

10. Baffoun N, Lakhdhar R, Baccar K, Djebari K, Kaddour C. Cardiac injury in traumatic subarachnoid hemorrhagea: prospective study in 35 patients. Tunis Med. 2011;89(2):184187. 